\title{
Chronic Abdominal Pain from Disseminated Splenosis
}

\author{
Michael A. Santos, $M D^{1,2}$ \\ 'WellSpan Good Samaritan Hospital, Lebanon, PA, USA; ${ }^{2}$ Penn State Milton S Hershey Medical Center, Hershey, PA, USA.
}

KEY WORDS: clinical image; abdominal mass; disseminated splenosis; nuclear scintigraphy.

J Gen Intern Med 33(6):976-7

DOI: $10.1007 / \mathrm{s} 11606-018-4414-\mathrm{x}$

(C) Society of General Internal Medicine 2018
Patients with DS may retain partial immunoprotection from encapsulated organisms, ${ }^{6}$ but no studies have shown an optimal approach to assessing residual splenic function. ${ }^{7}$

Corresponding Author: Michael A. Santos, MD; WellSpan Good Samaritan Hospital, Lebanon, PA, USA

Compliance with ethical standards:

Prior presentations: None.

Conflict of Interest: The author declares that he does not have a conflict of interest.

\section{REFERENCES}

1. Short NJ, Hayes TG, Bhargava P. Intra-abdominal splenosis mimicking metastatic cancer. Am J Med Sci 2011;341:246-9.

2. Connell NT, Brunner AM, Kerr CA, Schiffman FJ. Splenosis and sepsis: the born-again spleen provides poor protection. Virulence 2011;2:4-11.

3. Schiff RG, Leonidas J, Shende A, Lanzkowski P. The noninvasive diagnosis of intrathoracic splenosis using technetium-99m heat-damaged red blood cells. Clin Nucl Med 1987;12:785-7.

4. Horger M, Eschmann SM, Lengerke C, Claussen CD, Pfannenberg C, Bares R. Improved detection of splenosis in patients with haematological disorders: the role of combined transmission-emission tomography. Eur $\mathrm{J}$ Nucl Med Mol Imaging 2003;30:316-9.

5. Lake ST, Johnson PT, Kawamoto S, Hruban RH, Fishman EK. CT of splenosis: patterns and pitfalls. AJR Am J Roentgenol 2012;199:W686-93.

6. Pearson HA, Johnston D, Smith KA, Touloukian RJ. The born-again spleen. Return of splenic function after splenectomy for trauma. N Engl J Med 1978;298:1389-92.

7. de Porto AP, Lammers AJ, Bennink RJ, ten Berge IJ, Speelman P, Hoekstra JB. Assessment of splenic function. Eur J Clin Microbiol Infect Dis 2010;29:1465-73. 


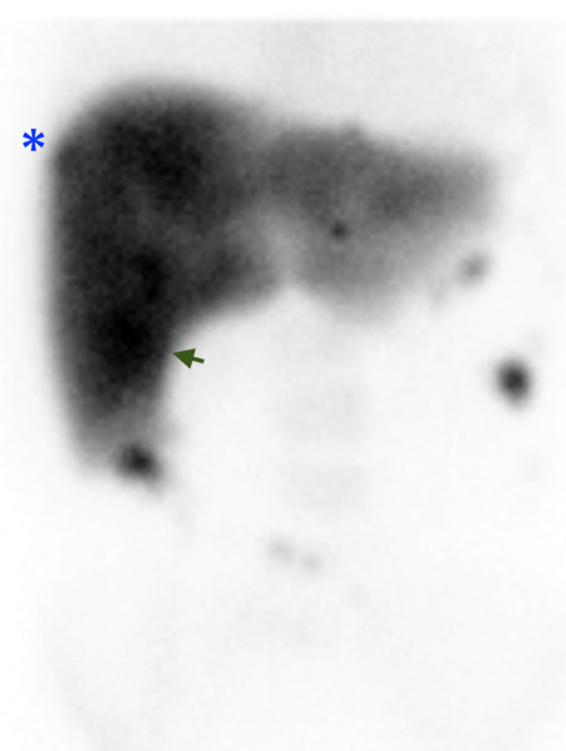

Anterior

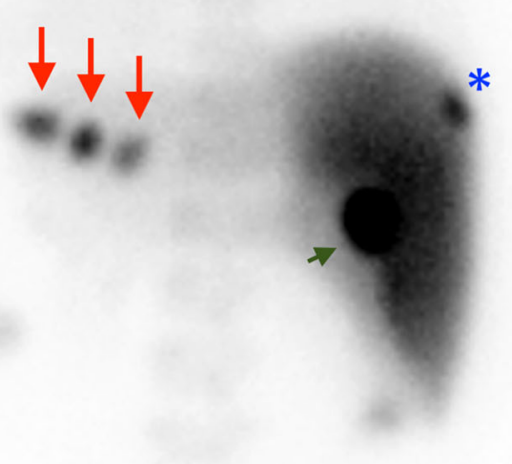

Posterior

Fig. 1 Maximum intensity projection (MIP) anterior and posterior images of $\mathrm{Tc}^{99} \mathrm{~m}$ scan showing increased radiotracer uptake in three separate splenic tissue deposits in the left upper quadrant measuring $2.3,2$, and $1.5 \mathrm{~cm}$ (red arrows), a $1.7 \mathrm{~cm}$ subphrenic deposit beneath the right diaphragm (blue star), and a $3 \mathrm{~cm}$ deposit posterior to the right kidney (green arrowhead), all correlating with her sites of discomfort. 